\title{
ARCHITECTURE BEHAVIOR
}

\author{
IF.Bambang Sulistyono Sk ${ }^{1}$, Yayan Suherlan ${ }^{2}$ \\ ${ }^{1}$ Faculty of Art and Design, Universitas Sebelas Maret, Indonesia \\ ${ }^{2}$ Faculty of Art and Design, Universitas Sebelas Maret, Indonesia \\ ${ }^{1}$ ifbambang@staff.uns.ac.id, 22yayansrm@gmail.com
}

\begin{abstract}
The basic process that involves human interaction and their environment is environmental information obtained by the process of perception. Perception is formed from a person's interaction with their living spaces which is finally manifested in their behavioral attitudes. Thus, behavior, response and action are determined by personal perceptions. It can be argued that human behavior is determined by human psychological state in the forms of condition, attitude, perception, cognition, and motivation. The cognition is obtained from each person's culture, experience, and education. The cognitionaspect is a transition because the information received will determine the feeling and willingness to make an action. Cognition consists of several components, namely cognitive components that answer the question of what people think about an objects,conation affection components that answer the question ofhow people feel about an objectand how a person is willing to act towards the object. Each component does not stand individually but as one unity called cognition system. Cognition system is the result of a cognitive process. It consists of perception, imagination, thought, reasoning and decision making activities.
\end{abstract}

Keywords: Human, Architecture, Behavior, Perception, cognition.

\section{INTRODUCTION}

The basic process involving human interaction with the environment is the reception of information about the environment through the process of perception. A person's perception is determined by experience, and experience is influenced by culture, and what is meant by cultural influence is their living habit [1].

Perception is formed from the interaction of a person (individual) with their living space which is finally manifested in their attitude behavior. Likewise, the behavior behind a person's attitude, human responses and actions are largely determined by the individual perception of the person. It can be said that human behavior is determined by their mental conditions in the form of attitudes, perceptions, cognition, and motivation. Cognition is obtained from culture, experience, and education undergone by individuals. The cognition aspect is the driving force for change, because the information that a person receives determines their feeling and willingness to take an action. Cognition consists of several components namely; the cognitive component that answers the question of "what someone thinks or perceives towards an object," the affection conation component that answers the question of "what someone feels (like/dislike) towards an object," and the conation component that answers the question of "how someone's willingness is to take action towards an object." 
There is some research about suggesting that people will be more active in buildings that visible, accessible, pleasing, and suppertive feature, such as motivational point of decision to physical activity, and suggest a framework to connecting research and implementation strategies for creating activity-friendly buildings[2]. Also, the built environment should adapt into the different needs in this rapidly changing era on technological revolution in order to order to understand how does the old urban fabric, which was originally formed as reflection and translation to a past culluture, emphasize the important of utilizing the knowledge of human behavior designing built environments[3].

Each of these components does not stand individually but is a unity which is referred to as cognition system. Cognition system is the result of cognitive processes consisting of perception, imagination, thinking, reasoning and decision making activities.

\section{METHOD}

Lang stated that one cannot understand a person's behavior towards a space without understanding the cognition map experienced by the person and utilize it to understand their behavior [4].

Behavioral approach emphasizes the dialectical relationship between space and humans and the people who use or inhabit the room. This approach emphasizes the need to understand human or community behavior (which varies by region) in utilizing space. The space in this approach sees that different aspects of norms, culture, psychology, society will produce different concepts and forms. Because the emphasis is more on interaction between humans and space [5].

In turn, all these factors will be interconnected as a system that will affect the way a person perceives an environment. Perception is an important element in spatial psychology. Perception is the meaning generated from the results of observations through the absorption of information about the environment through the five senses which includes perceptions of the environment as a whole, both the environment where an individual lives and where he grew up. In short, perception can be interpreted as an observation that is directly associated with meaning. Environmental conditions are stimuli in the process of perception. After getting stimuli, the selection process that interacts with interpretation will occur. Interpretation depends on experience (latest experience). From this interaction process, responses in the form of permanent memory is formed which is referred to as mental representation. Each person's perception will always be different or subjective. Because perception depends on the way a person perceives information.

\section{RESULT AND DISCUSSION}

\subsection{Human and Architecture}

The human needs will always develop according to the demands of their personality. This is explained by Maslow's theory of human need hierarchy that is depicted like a pyramid (from base to peak) consisting of: Physiological Needs, Security Needs, Socialization Needs, Appreciation needs, and Self Actualization needs [6].

For humans, having common sense is different from being rational. Ratio does not depend on the situation, whereas common sense depends on the situation. As creatures with common sense, humans tend to always try to understand their environment. And the tendency to always understand the environment is one of the characteristics of humans. However, the balance between common sense and ratio sought by each person is never the same for everyone, 
because in psychology, there is also a theory which states that each person is a unique individual who has his own way to react to the environment. Environmental psychology is the study of the responses given by living things to their environment [7].

Meanwhile, Bell argued that environmental psychology is the science of correlation between behavior with the environment, both artificial and natural. Holahan said that environmental psychology is a field of psychology that examines specifically the correlation between the physical environment with human behavior and experience [8].

Because the processing of environmental psychology does not only focus on human behavior but also on the correlation between human behavior with their physical environment, Kurt Lewin argued that behavior is the function of one's personal condition and the environment in which the person live.

Architectural design includes the stages of programming, planning, and designing. Programming deals primarily with gathering and organizing information needed in a structure's design. One of the most decisive information at the programming stage is the client (structure user). This includes the identity of the client, their background, demographic characteristics, behavior patterns, philosophy, history of operations, client development and so on. Great architects, who designed the best structures from the Gothic era to the humanist era of our time, were very sensitive regarding the defining aspects of architecture. The best structures of the historical times respond to human needs and feelings, not only in their time, but also as a developed social lifestyle.

However, many architectural structures still fail in terms of function or behavior. Structures that are considered successful can still be designed to be better if the architect is willing to pay attention to the needs of the user and the ways in which the artificial environment and interaction behavior work.

According to the cycle diagram that was firstly proposed by John Ziesel in architectural sociology, information and concepts of environmental behavior do not have an entrance to the designing process. Instead, the information and behavioral concepts are applied to policies, programming, and mostly, such decisions and designs are assessed regarding social behavior criteria in post-occupancy.

\subsection{Behavior And Environmental Perception}

The theory of Behavior and environment correlation consists of its nature and function, as well as some approaches such as environmental stress approach, arousal approach, environmental charge approach, surface adaptation theory and integration [9].

The theory of behavioral correlation consists of: theoretical function, Approach, Integration. One's answer (response) to the surrounding environment depends on how the person perceives his environment. There are several human perceptions regarding the environment.

\subsubsection{Personal space}

People perceive the surrounding space as a whole. If there is another person in the space, then they will immediately take a distance between themselves and the other people.According to Holahan there are four types of personal space [9] namely:

1. Intimate distance $(0-0,50 \mathrm{~m})$ : the distance for interacting with best friends or family members. 
2. Personal distance $(0.5-1,30 \mathrm{~m})$ : the distance for conversation between two close friends of a close person.

3. Social distance $(1.30-4.00 \mathrm{~m})$ : the distance to form a formal relationship such as business and others.

4. Public distance $(4,00-8,30 \mathrm{~m})$ : the distance for more formal relationships such as lectures and others.

The difference in distance above is also determined by: gender, age, personality, ethnicity or ethnic background, and the surrounding environment.

\subsubsection{Privacy}

Privacy is one's desire to reduce outside interference to a minimum level or the tendency of oneself to not be disturbed. There are two categories of privacy, namely:

1. The desire not to be physically disturbed. This category consists of three types:

a. the desire to be alone (solitude),

b. desire to stay away from sight and distractions

c. desire for intimacy.

2. One's desire to maintain the confidentiality that is self manifested in behavior of only only giving information that is considered necessary.

\subsubsection{Territoriality}

Territoriality is the manifestation of an ego that does not want to be disturbed. Holahan argued that territoriality is: a behavioral pattern related to ownership or a person or group of people's rights over certain place or geographical location. This behavioral pattern includes personalization and defense against outside interference [8], There are three types of territoriality, namely:

1. Primary territory, places that are very private and should only be entered by people who are familiar.

2. Secondary territory, which is a place that is shared by a number of people who already know each other.

3. Public territory, which is a place open to the public where everyone is allowed to be in that place.

\subsubsection{Crowding and Density}

Holahan argued that density is spatial constraints, while crowding is subjective response to tight space. There are two characteristics of the correlation between density and crowding, namely: crowding is the perception of density in terms of human numbers. Crowding is subjective perception. There are four types of density [8] namely:

1. Rural density: high density inside the house, while outside density is low.

2. Suburb density: high density inside and outside the house.

3. Slum density : high density inside and outside the house is high.

4. Luxurious home density: density inside the house is low, while outside is high.

\subsubsection{Mental Map}


Holahan mentioned that mental map is the processes that allow memory storage, recalling as well as recompiling information about real locations and signs of geographical environment [9]. There are several types of mental maps, namely:

1. Land mark.

2. Paths that connect one place to another.

3. Intersection points between paths (nodes) such as: intersection, junction.

4. Edges that distinguish one area with other regions.

5. District: a homogeneous region that is different from other regions.

There are several factors that distinguish mental maps, namely: lifestyle, familiarity with environmental conditions, social familiarity, social class, and gender.

\subsubsection{Stress}

After an individual perceives stimuli from his environment, there are two possibilities that can occur. The first possibility is that the stimuli are perceived within the tolerance threshold of the individual which causes the individual to be in a homeostatic state. The second possibility is that the stimuli are perceived beyond the tolerance threshold that causes stress on the individual.

Thus the perception of the environment is very influential on human behavior and on space. This means that the tendency regarding space perception is very much needed by people in connection with the virtual boundaries that must be owned or spaces that should not be disturbed by others. In term of space, constraints also need to be taken into account by paying attention to the space comfort aspects so that the behavior of people who occupy it is not affected by stress.

\section{CONCLUSION}

The basic process involving human interaction with the environment is the reception of environmental information through the process of perception [4].The successful design for achieving walfare and happiness of interior architecture depends on how designers find balance between the dominant factors such as identity, privacy, safety, accessibility, functionality, flexibility, community interaction, and the provision of adequate, should be given due weight [10].

Perception is formed from a person's interaction with their living spaces which is eventually manifested in their behavioral attitudes. Like the behavior behind a person's attitude, human responses and actions are largely determined by the individual's perception [11].

It can be said that human behavior is determined by their mental conditions in the form of attitudes, perceptions, cognition, and motivation. Cognition is obtained from culture, experience, and education undergone by the individuals. The cognition aspect is the driving force for change, because the information that a person receives determines their feeling and willingness to take an action. Cognition consists of several components namely; the cognitive component that answers the question of "what someone thinks or perceives towards an object," the affection conation component that answers the question of "what someone feels (like/dislike) towards an object," and the conation component that answers the question of "how someone's willingness to take action towards an object is." 
Each of these components does not stand individually but as a unity which is referred to as cognition system. Cognition system is the result of cognitive processes consisting of perception, imagination, thinking, reasoning and decision making activities.

\section{REFERENCES}

[1] Suwondo. Arsitektur, Manusia, Dan Pengamatannya, Jakarta: Djambatan Press. 1986.

[2] zimring, craig, etc. Infulences of Building design and site design on physical activity. Research and intervension opportunities. American Journal of preventive medicine. Volume 28, number 252.

[3] Mahmoud, AmiraMersal. The Impact of Builenvironment on human Behaviors. Environmental Science and Sustainable and Development. 2018.

[4]Lang, John. Designing For Human Behavior. Hut-Chinson: Dowden Press. 1978.

[5] Lawrence, Joyce Marcella. ArsitekturdanPerilakuManusia. Jakarta: Grasindo. 2004.

[6] Clovis. Behavior Architect. America: The United States Of amerika Press. 1977.

[7] Sarlito. Psikologi Lingkungan.Jakarta: Grasindo Press. 1992.

[8] Holahan. Environmental Psycology. New York: Random house Inc. 1982.

[9] Snyder, J.C.. Introduction Architecture. London: The Architectural Press. 1979.

[10] Mahmoud, HebaTallaHamdy. Interior Architectural Elements that Affect Human and Psycology and Behavior.The Academic Research Publication. The International Conference: Citie'sindentity through architecture and art (CITAA). 2010.

[11] R. Rahim, N. Kurniasih, GS, A. D., K. Saddhono, B.K. Riasti, I.B. Rangka, I. B., ... \& M.G.R. Pandin. "Random and match game for education purposes with model learning technology system architecture". In IOP Journal of Physics: Conference Series vol. 1179 no. 1, pp. 012038. IOP Publishing. 2019 